\title{
Simple excision for the management of limbal dermoids in young children
}

Veronique Promelle, Christopher J Lyons, University of British Columbia Department of Ophthalmology and Visual Sciences, Canada

\section{Introduction}

Dermoids are the most common limbal tumor in childhood: they may cause amblyopia through induced astigmatism and/or encroachment of the visual axis.

They may also cause irritation, discomfort and, because of their appearance, they can be a cause of stigma for the child.

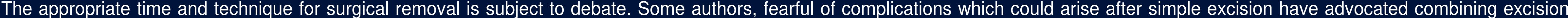
with the use of amniotic membrane graft, mitomycin-C or lamellar keratoplasty ${ }^{1,2}$

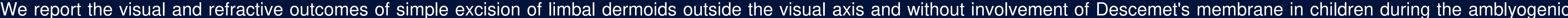
period. Dermoids were dissected off the corneal surface, allowing re-epithelialization.

\section{Methods}

Retrospective chart review of al

patients aged less than 8 year

undergoing limbal dermoid excision

under our care from 2000 to 2019.

Results

19 patients

8 (42\%) female; 8 (42\%) right eyes

Average follow-up [range] $4.0 \mathrm{y}[1 \mathrm{mo}-12 \mathrm{y}]$

Indication for surgery

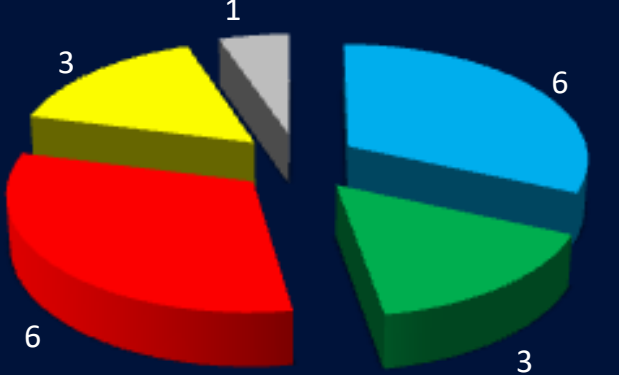

u cosmesis, $\mathrm{n}=6$

astigmatism, $\mathrm{n}=3$

amblyopia, $n=6$

discomfort, $n=3$

unspecified, $n=1$

Age at surgery

Mean age [range] : 4.2y [9 mo - $8 \mathrm{y}]$

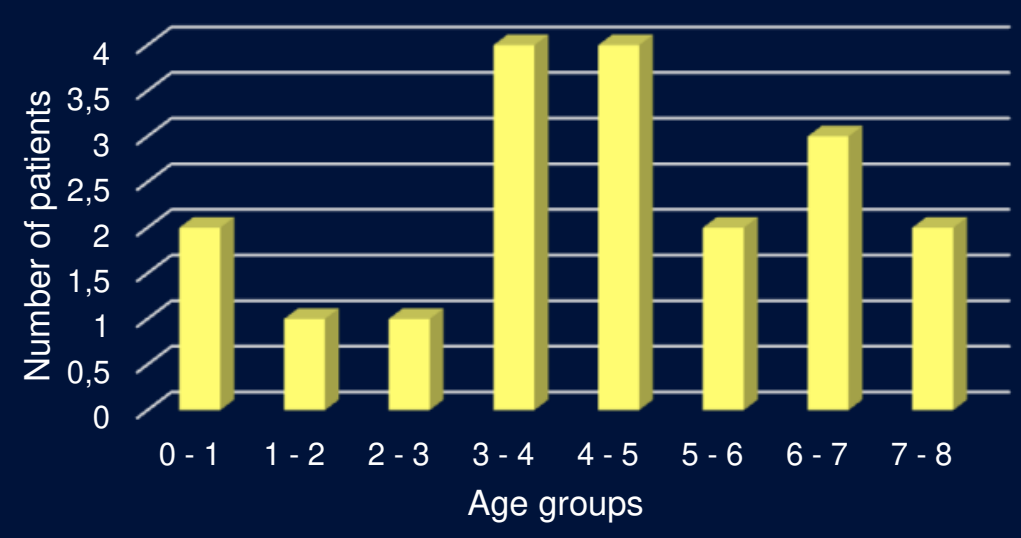

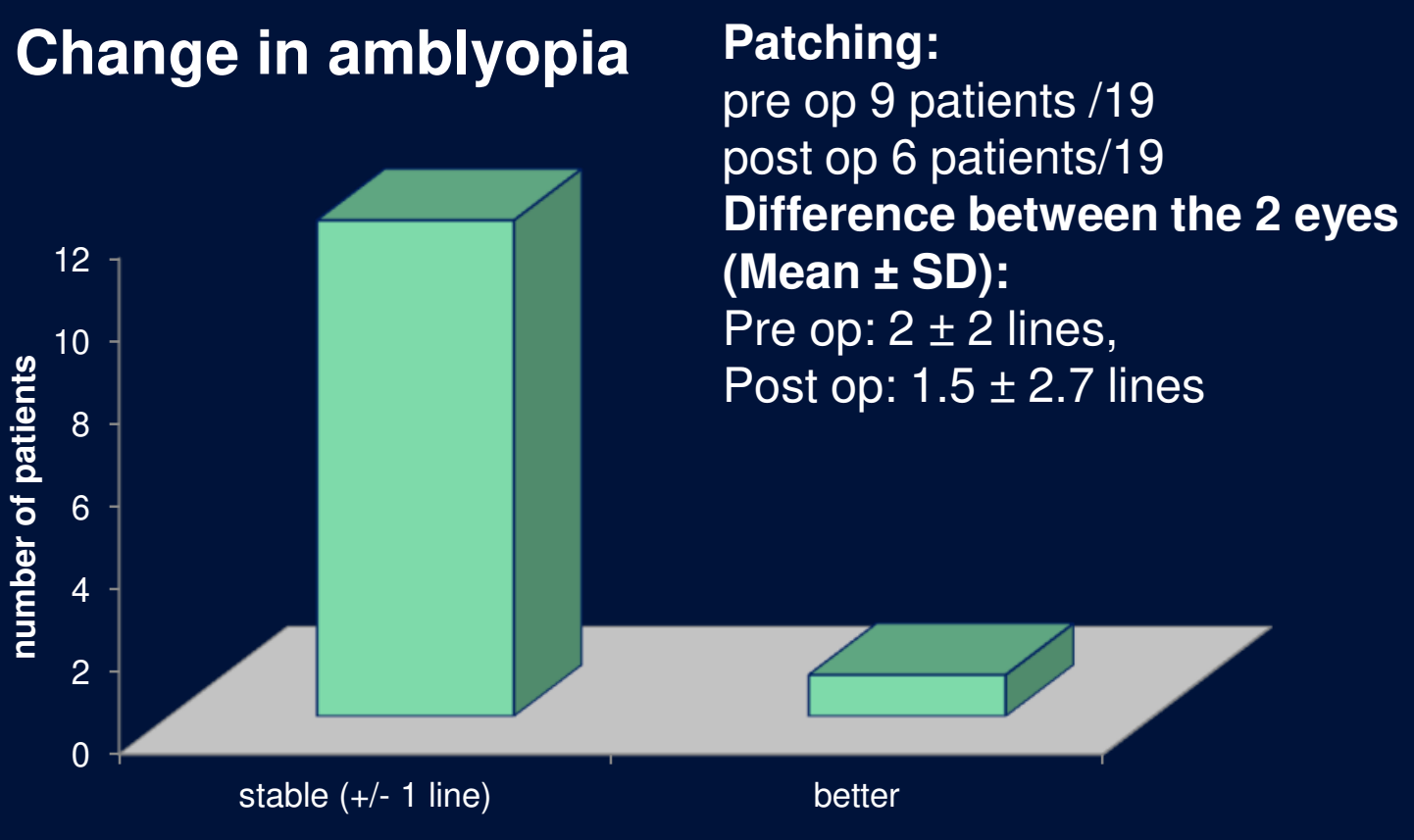

Mean \pm SD Visual Acuity pre op $0.32 \pm 0.27$ post op $0.3 \pm 0.52$

Mean change in visual acuity $:+1$ line

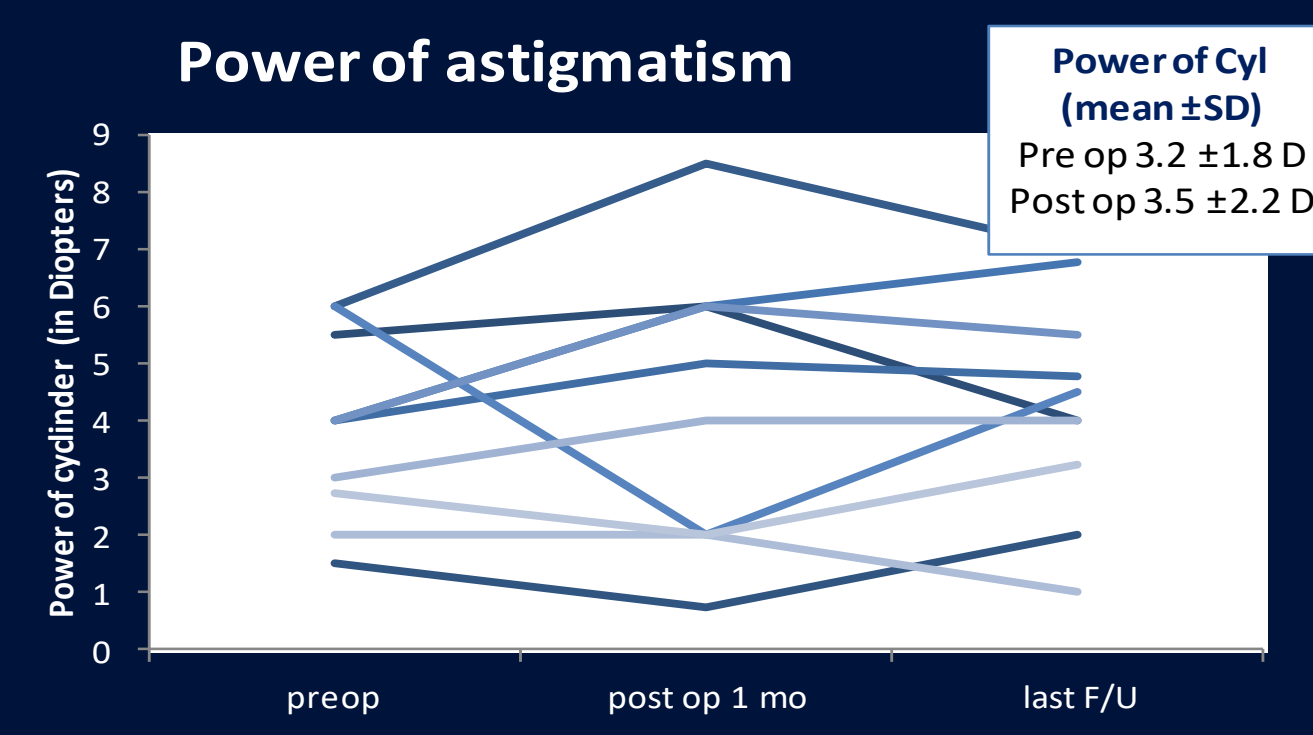

Post operatively :

- 1 patient had residual dermoid tissue

- All patients showed conjunctivalization of corneal scar, which took up to 3 weeks to heal. The epithelial cover became more transparent with time. -The cosmetic outcome was good

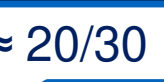

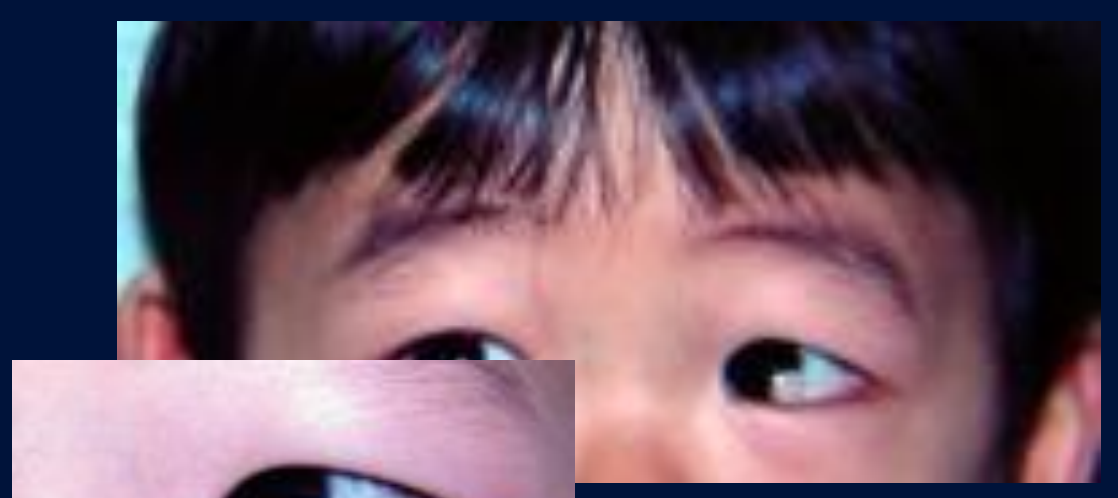

This patient with astigmatism of $3.00 \mathrm{D}$, no amblyopia, underwent excision of a dermoid LE at the age of $3 y$.
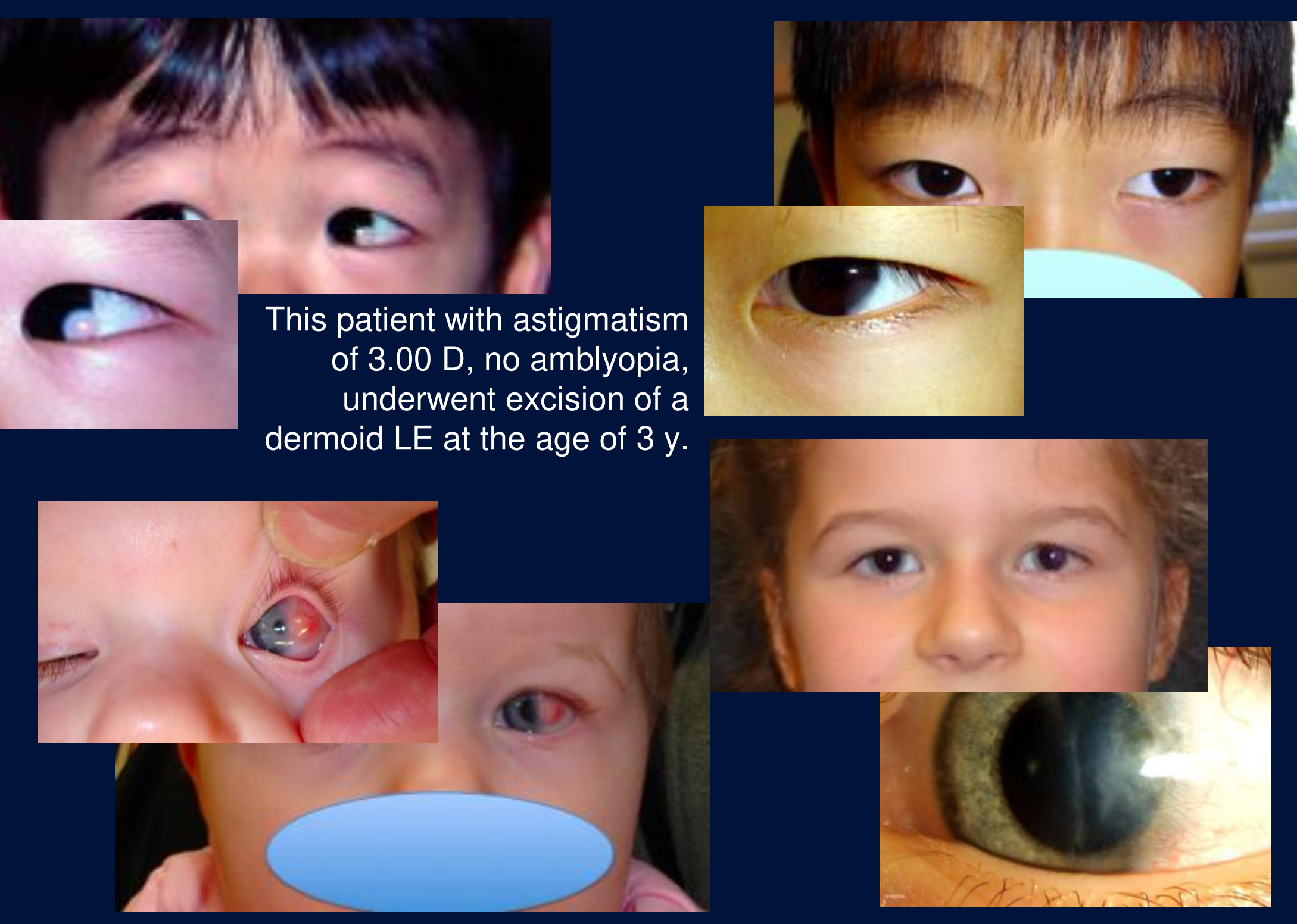

This patient underwent excision of a large dermoid LE at the age of 10 months. The astigmatism of 3.00 D was corrected with glasses and amblyopia treated with patching. After 6 years of follow-up the VA was 20/30 and cosmesis was much improved

\section{Conclusions}

$>$ Simple excision is a safe procedure with good cosmetic outcome

$>$ But doesn't affect significantly

- The visual acuity or amblyopia

- The power or axis of astigmatism

The complications justifying more aggressive procedures such as deep amellar keratoplasty or the use of Mitomycin-C, were not encountered afte this simple procedure 